\title{
Hysterosalpingography in Infertility
}

\author{
Masuda Islam Khan1, Suha Jesmin², Jesmin Jerin², Shahana Shermin'4, T A Chowdhury5
}

\begin{abstract}
Background: Infertility is a common medical problem. It can be due to problems in either partner, or both. Ovulatory dysfunction, tubal and peritoneal factors comprise the majority of female factor for infertility. Hysterosalpingography (HSG) plays an important role in the evaluation of abnormalities related to the uterus and fallopian tubes. Objective: The aim of this study was to evaluate the hysterosalpingographic findings of women with infertility in our setting. Materials and method: This cross sectional study was carried out in the infertility centre at BIRDEM, Dhaka, Bangladesh during the period of September 2002 to February 2003. Out of 100 infertile patients 50 infertile women of reproductive age (21-40 years) indicated for HSG were enrolled in this study. Results: Sixty percent patients had secondary infertility. Majority of the subjects of both primary and secondary infertility (55\% and 60\%) were in 26-30 years age group. On HSG any sort of uterine pathology was found in $10 \%$ cases and unilateral and bilateral tubal block were present in $24 \%$ and $20 \%$ cases respectively. Conclusion: Hysterosalpingography, a safe, less invasive procedure, has an important role in diagnosing uterine and tubal factors of infertility.
\end{abstract}

Keywords: Hysterosalpingography; infertility.

Delta Med Col J. Jan 2014;2(1):9-12

1. Registrar, Department of Gynae \& Obstetrics, BIRDEM, Dhaka, Bangladesh.

2. Assistant Professor, Department of Gynae \& Obstetrics, Anwar Khan Modern Medical College, Dhaka, Bangladesh.

3. Senior Medical Officer, Department of Gynae \& Obstetrics, BIRDEM, Dhaka, Bangladesh.

4. Senior Medical Officer, Department of Gynae \& Obstetrics, BIRDEM, Dhaka, Bangladesh.

5. Professor of Gynae \& Obstetrics, BIRDEM, Dhaka, Bangladesh.

Correspondence: Dr. Masuda Islam Khan. e-mail: masudaislamkhan@yahoo.com

\section{Introduction}

The desire for reproduction is a basic human right. Though the population burden is the big problem in our country, on the other hand infertility is not an uncommon problem. The number of infertility visit has increased over the past decades. ${ }^{1}$

Infertility is defined as the inability of a couple to conceive within one year with regular unprotected intercourse. Infertility is synonymous with sub fertility and implies a decrease in the ability to conceive. Primary infertility applies to those who have never conceived, whereas secondary infertility designates those who have conceived at sometime in the past. 1
The prevalence of women diagnosed with infertility is approximately $13 \%$, with a range from $7-28 \%$. It has remained stable over recent years.1,2 However the incidence of primary infertility has increased with a concurrent decrease in secondary infertility most likely as a result of social changes such as delayed child bearing.

Infertility can be due to problems in either partner, or both. The male is responsible in about $30-40 \%$, the female in about $40-55 \%$ and both are responsible in about $10 \%$ cases. The tuboperitoneal factors are responsible in about $30-40 \%$ cases of female infertility 
and hence evaluation of tubal patency represents a key step and a basic investigation in the assessment of infertile women. $3-5$

Hysterosalpingography (HSG) is a fluoroscopic study performed by instilling radiopaque dye into the uterine cavity through a catheter to determine the contour of the uterine cavity and patency of the fallopian tubes. 1,3 It is a less invasive, reliable and the most commonly used first line investigation in the evaluation of the female genital tract in infertility. ${ }^{3-7}$ It has been extensively employed in infertility investigations since its first application by Carey in $1914 .{ }^{8}$

Hysterosalpingography can be obtained in an outpatient setting, with minimal analgesia consisting of premedication with a non steroidal anti-inflammatory drug (NSAID). The test is usually scheduled for the interval after menstrual bleeding and prior to ovulation. Either water or oil based dye may be selected. There is some evidence that the use of an oil based dye may have a fertility enhancing effect at least for the first few cycles. A HSG is contraindicated in the presence of an adnexal mass, pelvic inflammatory disease, with history of ectopic pregnancy or an allergy to iodine or radiocontrast dye. Uterine abnormalities that can be detected at HSG include congenital anomalies, intrauterine polyps, submucous leiomyomas, surgical changes and synechiae. Tubal abnormalities that can be detected include proximal or distal tubal occlusion, salpingitis isthmica nodosum, polyps, hydrosalpinx and peritubal adhesions. $1,3,5,8-10$

The goal of this study was to evaluate the hysterosalpingographic findings of women with infertility in our setting.

\section{Materials and method}

It was a cross sectional study carried out from September 2002 to February 2003, in Infertility Care Centre at Bangladesh Institute of Research \& Rehabilitation in Diabetes, Endocrine and Metabolic disorders (BIRDEM), Dhaka, Bangladesh.

Out of 100 infertile patients 50 infertile women of reproductive age (21-40 years) indicated for hysterosalpingography (by history, clinical assessment and USG findings) were randomly selected in this study. Couple with male factor infertility and patients with any contraindication for HSG i.e. recent pelvic infection, allergy to oil based dye were excluded. HSG using oil based dye was done after menstrual flow has ceased but before the patient had ovulated i.e. by day 7 to day 10 of the menstrual cycle. The clinical assessment was done with a thorough history of both partners and was documented in preset data sheet. Female history included menstrual history, past obstetrical history and past medical or surgical history were also documented. Thorough physical examination was done to exclude any apparent anatomical abnormality. Collected data were compiled and expressed as proportion.

\section{Results}

Table I shows that $40 \%$ couple had primary infertility and $60 \%$ had secondary infertility.

Table I: Types of infertility $(\mathrm{N}=50)$

\begin{tabular}{lcc}
\hline Types & Frequency & Percentage \\
\hline Primary & 20 & 40.0 \\
Secondary & 30 & 60.0 \\
\hline
\end{tabular}

Table II shows, majority of women (55\% and $60 \%)$ were in age group 26-30 years for both primary and secondary infertility group.

Table II: Age distribution of the subjects $(\mathrm{N}=50)$

\begin{tabular}{ccc}
\hline $\begin{array}{c}\text { Age Group } \\
\text { (years) }\end{array}$ & $\begin{array}{c}\text { Primary } \\
\text { infertility } \\
(\mathbf{n}=\mathbf{2 0})\end{array}$ & $\begin{array}{c}\text { Secondary } \\
\text { infertility } \\
(\mathbf{n}=\mathbf{3 0})\end{array}$ \\
\hline $21-25$ & $3(15 \%)$ & $6(20 \%)$ \\
$26-30$ & $11(55 \%)$ & $18(60 \%)$ \\
$31-35$ & $5(25 \%)$ & $4(13.3 \%)$ \\
$36-40$ & $1(5 \%)$ & $2(6.6 \%)$ \\
\hline
\end{tabular}

Majority (46\%) of the cases reported at the infertility centre within 2-5 years of unsuccessful attempt of pregnancy (Table III).

Table III: Duration of infertility $(\mathrm{N}=50)$

\begin{tabular}{lcc}
\hline Duration (years) & Frequency & Percentage \\
\hline $1-2$ & 12 & 24.0 \\
$2-5$ & 23 & 46.0 \\
$5-10$ & 10 & 20.0 \\
$>10$ & 5 & 10.0 \\
\hline
\end{tabular}

Table IV shows, regular cyclical menstruation occurred in $70 \%$ cases whereas irregular in $28 \%$ cases. 
Table IV: Distribution of menstrual pattern $(\mathrm{N}=50)$

\begin{tabular}{lcc}
\hline Menstrual pattern & Frequency & Percentage (\%) \\
\hline Regular & 35 & 70.0 \\
Irregular & 14 & 28.0 \\
Withdrawal bleeding & 1 & 2.0 \\
\hline
\end{tabular}

Most of the women $(60 \%)$ had no significant past history. Surgical interference was found in $12 \%$ cases followed by puerperal sepsis in $18 \%$ cases, diabetes mellitus in $8 \%$ cases and tuberculosis in $2 \%$ cases (Table V).

Table V: Pattern of history of past illness $(\mathrm{N}=\mathbf{5 0})$

\begin{tabular}{lcc}
\hline Past illness & Frequency & Percentage (\%) \\
\hline Puerperal sepsis & 9 & 18.0 \\
Tuberculosis & 1 & 2.0 \\
Diabetes Mellitus & 4 & 8.0 \\
Surgical interference & 6 & 12.0 \\
None & 30 & 60.0 \\
\hline
\end{tabular}

Table VI shows, 90\% women had anatomically normal uterus, $2.0 \%$ had unicornuate uterus and $8 \%$ had irregular shaped uterine cavity. Regarding tubal condition, $56 \%$ had patent tubes on both sides, unilateral block in $24 \%$ cases and $20 \%$ cases had bilateral tubal block.

Table VI: Findings of hysterosalpingography $(\mathrm{N}=50)$

\begin{tabular}{lcc}
\hline Parameters & Frequency & Percentage (\%) \\
\hline Uterine shape & & \\
$\quad$ Unicornuate & 1 & 2.0 \\
$\quad$ Irregular cavity & 4 & 8.0 \\
$\quad$ Normal & 45 & 90.0 \\
Tubal condition & & \\
$\quad$ Both tubes patent & 28 & 56.0 \\
$\quad$ Unilateral block & 10 & 24.0 \\
Bilateral block & 12 & 20.0 \\
\hline
\end{tabular}

\section{Discussion}

In this study we found that most of the women undergoing hysterosalpingography had secondary infertility. Similarly secondary infertility was found to be commoner than primary in some other studies done abroad. 6,12
The majority of both the primary and secondary infertility groups were in the age range of 26-30 years which is supported by studies done by Kiguli-Malwadde and Byanyima ${ }^{6}$ and Haider et al. ${ }^{13}$

In majority of cases duration of infertility was 2-5 years. In the studies done by Haider et al.13, Santhalia et al.5, Abdalla14 and Kabala12 mean duration of infertility at the time of presentation were $>2$ years, 3.9 years, 3-8 years and 5 years respectively.

In this study we found $70 \%$ subjects had normal menstrual cycle and $24 \%$ patients had irregular cycle. Similar findings were observed by Haider et al. 13

Regarding past illness, $18 \%$ had history of puerperal or post abortal infection. This differs from study done by Shayela 15 , where puerperal sepsis was present in $30 \%$ cases. Though both the studies were done in two tertiary care hospitals, the time interval is more than one decade which reflects a remarkable improvement in antenatal, intranatal, post natal and post abortal care.

On HSG, we found that most cases had normal uterine cavity, a minor proportion with irregular uterine cavity with a space occupying lesion and uterine anomaly was the least. These findings are in accordance with studies done by Santhalia et al. 5 , Kabala ${ }^{12}$, Mesbahi et al. ${ }^{16}$ and Sakar et al. ${ }^{17}$ On the other hand a good percentage $(44 \%)$ of subjects had either bilateral or unilateral tubal block. These findings are also supported by a number of studies. ${ }^{5,18-21}$

It is widely accepted that infertility is a common medical problem. There are several tools for detection of the causative factors of infertility which are widely available now a days. In a developing country like ours hysterosalpingography may still play an important role in diagnosing uterine and tubal factors of infertility and may avoid further expensive, invasive procedures and relieve the sufferers from the agonizing state of childlessness.

\section{References}

1. Kumar A, Ghadir S, Eskandari N, DeCherney AH. Infertility. In: DeCherney AH, Nathan L, Goodwin TM, Laufer N, editors. Current Diagnosis \& Treatment Obstetrics \& Gynecology. 10th ed. New York: McGraw-Hill; 2007. p.917-22.

2. Nicopoullos JD, Croucher CA. Audit of Primary Care and Initial Secondary Care Investigations Set Against RCOG Guidelines as Standard in Cases of Subfertility. J Obstet Gynaecol. 2003;23:397-401. 
3. Lim CP, Hasafa Z, Bhattacharya S, Maheshwari A. Should a Hysterosalpingogram Be a First-Line Investigation to Diagnose Female Tubal Subfertility in the Modern Subfertility Workup? Hum Reprod. 2011;26(5):967-71.

4. Dutta DC. Infertility. In: Konar H, editor. Textbook of Gynaecology. 5th ed. Kolkata: New Central Book Agency; 2008. p.220-21.

5. Santhalia PK, Gupta MK, Uprety D, Ahmad K, Ansari S, Agrawal N, Rauniyar RK. Role of Radiographic Hysterosalpingography in Infertility in Eastern Nepal. Nepalese Journal of Radiology. 2013;13(1):59-66.

6. Kiguli-Malwadde E, Byanyima RK. Structural Findings at Hysterosalpingography in Patients with Infertility at Two Private Clinics in Kampala, Uganda. Afr Health Sci. 2004;4(3):178-81.

7. Kumar P. Infertility. In: Arulkumaran S, Gopalan S, Kumar P, editors. Obstetrics and Gynecology for Postgraduates. Vol.2, 3rd ed. Hyderabad: Universities Press; 2009. p.123.

8. Bendick AJ. Present Status of Hysterosalpingography. Journal of the Mount Sinai Hospital, New York. 1947;14(3):739-42.

9. Jeffcoate N. Infertility and Assisted Reproductive Technology. In: Kumar, Malhotra N, editors. Jeffcoate's Principles of Gynaecology. 7th ed. New Delhi: Jaypee Brothers Medical Publishers (P) Ltd; 2008. p.710.

10. Johnson NP, Farquhar CM, Hadden WE, Suckling J, Yu Y, Sadler L. The FLUSH Trial - Flushing with Lipiodol for Unexplained (and endometriosis related) Subfertility by Hysterosalpingography: A Randomized Trial. Hum Reprod. 2004;19:2043-51.

11. Simpson WL Jr., Beitia LG, Mester J. Hysterosalpingography: A Reemerging Study. Radiographics. 1981;26:419-31.
12. Kabala RB. Imaging Findings in Infertile Female Patients Who Underwent Hysterosalpingography Investigation at Muhimbili National Hospital, Tanzania. [Masters thesis]. Tanzania: Muhimbili University of Health and Allied Sciences; 2011.

13. Haider G, Rani S, Talpur S, Zehra N, Munir A. Laparoscopic Evaluation of Female Infertility. J Ayub Med Coll Abbottabad. 2010;22(1):136-38.

14. Abdalla MN. Epidemiology of Infertility in Gezira Region, Central of Sudan. Research Journal of Medical Sciences. 2011;5(1):56-60.

15. Shayela S. A Clinical Study of 100 Cases of Infertility Attending the Infertility Clinic of IPGMR, Dhaka [dissertation]. Dhaka: Bangladesh college of Physicians of surgeons; 1989.

16. Mesbahi S, Pourissa M, Refahi S, Tabarraei Y, Dehghan MH. Hysterosalpingographic Abnormalities in Infertile Women. Research Journal of Biological Sciences. 2009;4(4):430-32.

17. Sakar MN, Gul T, Atay AE, Celik Y. Comparison of Hysterosalpingography and Laparoscopy in the Evaluation of Infertile Women. Saudi Med J. 2008;29(9):1315-18.

18. Moghissi KS, Sim GS. Correlation between Hysterosalpingography and Pelvic Endoscopy for Evaluation of Tubal Factors. Fertil steril. 1975;26(12):1178-81.

19. Tvarijonavieiene E, Nadisauskiene RJ. The Value of Hysterosalphingogram in Diagnosis of Tubal Pathology among Infertile Patients. Medicina (Kaunas). 2008; 44(6):439-48.

20. Bello TO. Tubal Abnormalities on Hysterosalpingography in Primary and Secondary Infertility. WAJM. 2006;25(2):130-33.

21. Okafor CO, Okafor CI, Okpala OC, Umeh E. The Pattern of Hysterosalpingographic Findings in Women Being Investigated for Infertility in Nnewi, Nigeria. Niger J Clin Pract. 2010;13(3):264-67. 